\title{
Report from the Second ACROSS International Symposium on Advances in Separation Science (ASASS 2016), Hobart, Nov 30th-Dec 2nd 2016
}

\author{
Brett Paull $^{1} \cdot$ Pavel N. Nesterenko ${ }^{1}$
}

Published online: 28 June 2017

(C) Springer-Verlag Berlin Heidelberg 2017

After a hiatus of eight years since the first ACROSS Symposium on Advances in Separation Science (ASASS 2008) was held in Hobart in 2008 to mark the 60th birthday of Prof. Paul Haddad, the second ACROSS International Symposium on Advances in Separation Science (ASASS 2016) opened its doors to an international delegation of separation scientists, both young and old, for three days of great science and social interaction. With close to 140 delegates (see Fig. 1), spanning local Australian based PhD students to internationally renowned experts, together originating from over 25 different countries, the meeting was an exciting mix of youth and experience, making for a hugely educational, productive and entertaining experience for all. The symposium was held within the Hobart Function and Conference Centre (HFCC), set upon the waterfront within a short walk to Hobart's Historic Salamanca place, with the symposium dinner held within the surrounds of the beautiful and unique Hobart botanic gardens (see Fig. 2). The first night of the symposium also involved a 'Great Aussie BBQ' held at the Hobart Waterworks Reserve, where delegates were exposed to the uniquely Aussie experience of sausage stealing kookaburras!

ASASS is a symposium organised and administered by the Australian Centre for Research in Separation Sciences (ACROSS), which is a research centre based upon a

Published in the topical collection 2nd ACROSS International Symposium on Advances in Separation Science (ASASS 2016) with guest editors Pavel Nesterenko and Brett Paull.

Brett Paull

brett.paull@utas.edu.au

1 Australian Centre for Research on Separation Sciences (ACROSS), School of Physical Sciences, University of Tasmania, Private Bag 75, Hobart, TAS 7001, Australia consortium of leading experts in separation science based across four Australian Universities, namely the University of Tasmania, Monash University, Western Sydney University and RMIT University. The symposium is run to expose the Australian based young and early career researchers to renowned separation scientists from both within Australia and across the globe. With this goal in mind the ASASS Organising Committee delivered an oral program with a large number of well-known national and international plenary, keynote and invited speakers, together with a significant number of presentations awarded to young Australian based researchers. In total, the three day scientific program packed in no fewer than 52 oral presentations and a similar number of posters.

The symposium kicked off with an excellent plenary presentation involving the application of separation methods, specifically ion chromatography, in the field of Antarctic Science. Dr Mark Curran of the Australian Antarctic Division and Antarctic Climate and Ecosystems presented a highly enjoyable and informative lecture on the tools at hand for discovering 'Climate signals frozen in Antarctica through chemical measurements on ice cores'. The three day program was then broken down into thematic sessions on all aspects of separation science, including Advances in Liquid Chromatography; Detection, Data, Modelling and Optimisation; Electrophoretic Methods; Extraction, Isolation and Mass Spectrometry; Green Chemistry and Environmental Applications; Multidimensional Chromatography and Coupled Techniques; Emerging Leaders and Young Separation Scientists; Advances and Applications of Gas Chromatography; Industrial/Pharmaceutical Applications and Natural Products; and Instruments, Interfaces and New Platforms. Each session began with an invited keynote presentation from a leading researcher in the area, these included Prof. Andrew Shalliker form the Western 


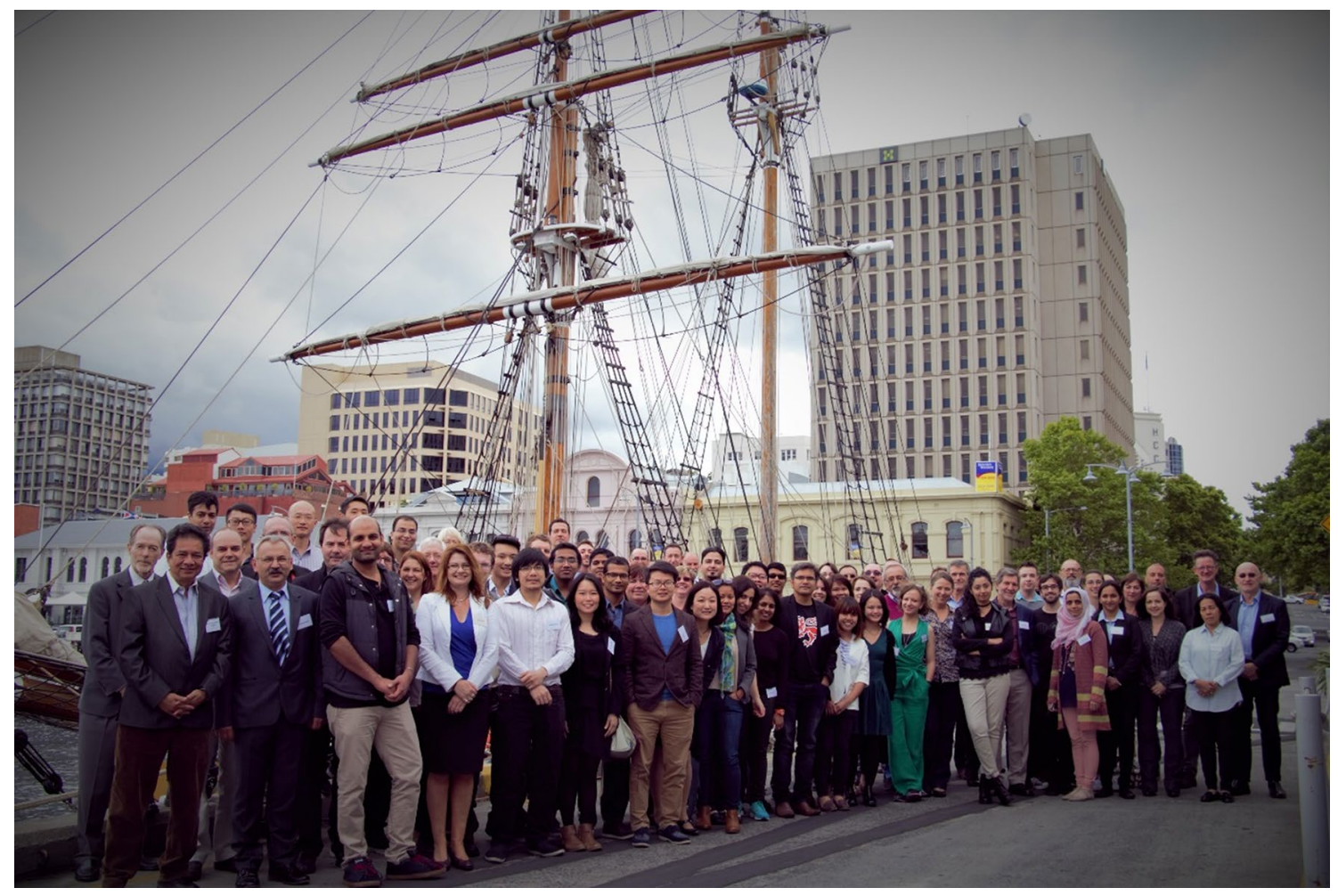

Fig. 1 ASASS 2016 delegates assembled 'afore the yardarm' at Hobart's historic Sullivan's Cove

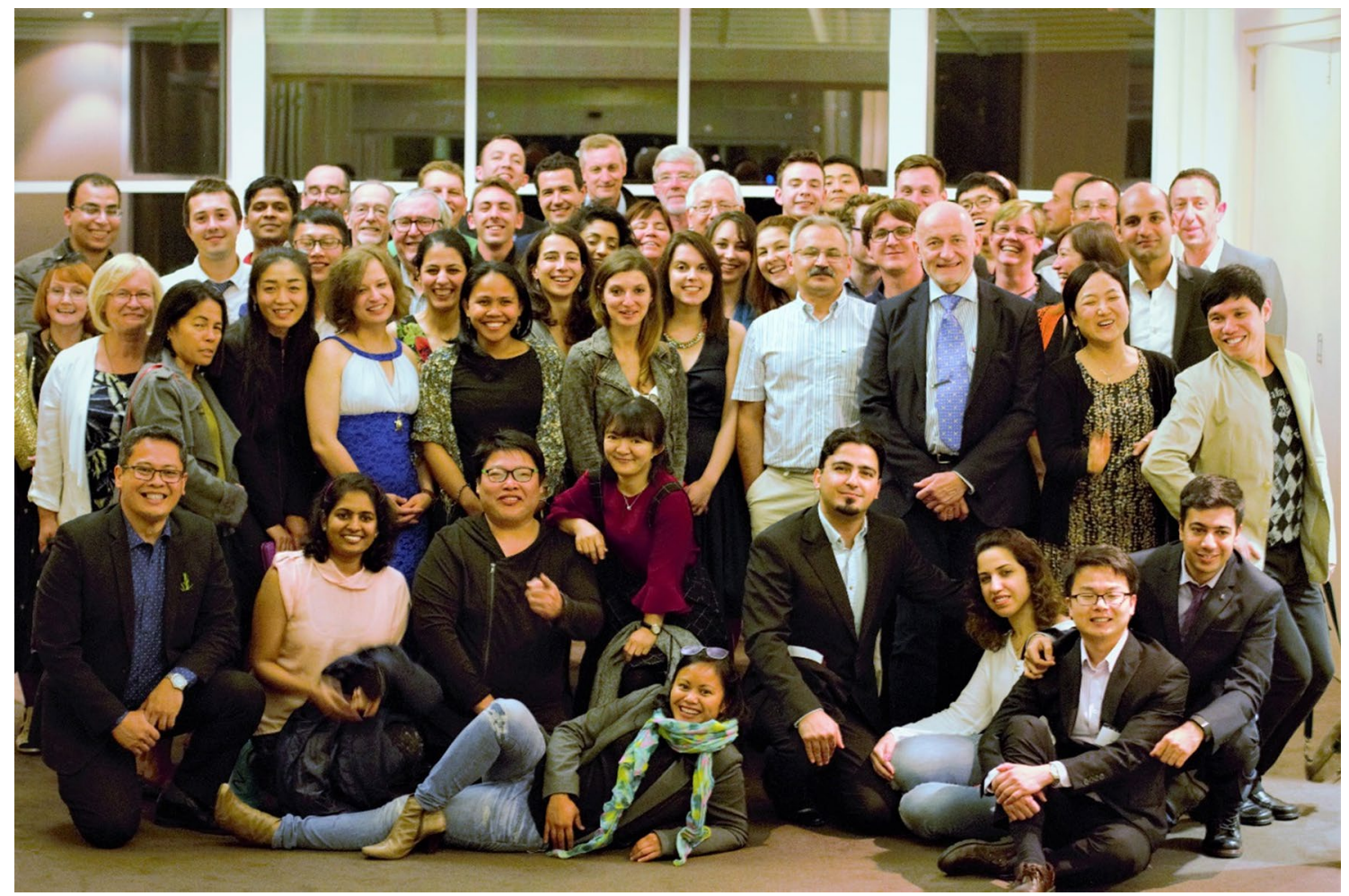

Fig. 2 Some of the ASASS 2 symposium dinner attendees at the Royal Botanic Gardens, Hobart 
Sydney University ('Realising high-speed separations and analysis'); Prof. Purnendu Dasgupta from the University of Texas at Arlington ('The axioms in chromatography shaken by fast data acquisition'); Prof. Michael Breadmore from the University of Tasmania ('Design and application of sequential injection—capillary electrophoresis systems'); Prof. Wolfgang Buchberger from the Johannes-Kepler University ( Novel mass spectrometric techniques for low- and high-performance chromatography'); Prof. Phillip Doble from the University of Technology, Sydney ('Microfluidic HPLC-Chip hyphenation to ICP-MS'); Prof. Peter Schoenmakers from the University of Amsterdam ('Multi-dimensional liquid chromatography_towards a million peaks'); Dr. Arianne Solivan from Novartis ('Maximising the peak capacity for complex reversed phase small molecule separations'); Prof. Phillip Marriott from Monash University ('A new paradigm in development of comprehensive-twodimensional gas chromatography separations based on a novel dual column primary dimension'); and Prof. JinMing Lin from Tsinghua University ('Generation of picolitre droplets of liquid for capillary electrophoresis and electrospray ionization').

The success of the symposium was of course heavily dependent upon the generous sponsorship of supporting organisations. These included, The Ian Potter Foundation; Trajan Medical and Scientific; Shimadzu Corporation; Waters Corporation; Agilent Technologies; Phenomenex; Kinesis Australia; and supporting publications, namely Chromatographia (Springer), Analyst, and Analytical Methods (RSC). Poster prizes were sponsored by Chromatographia, with the award of $\$ 400$ worth of book vouchers to the prize winners. The student three poster prizes were awarded to Chacriya Malasuk and co-workers (Mahidol University, Thailand), for their presentation entitled 'Determination of phenylalanine and tyrosine using micellor liquid chromatography' (\$100 Third Prize), Ibraam Mikhail and co-workers (University of Tasmania, Australia) for their presentation entitled 'Lab in a syringe' ( $\$ 100$ Second Prize), and Vipul Gupta and co-workers (University of Tasmania, Australia) for their presentation entitled '3D printed flow cells for chemiluminescence detection' $(\$ 200$ First prize). Thanks to the poster judges for their collective efforts, who included Prof Purnendu Dasgupta, Prof. JinMing Lin and Prof. Boguslav Buszewski.

The meeting closed with an invite from Prof. Phillip Marriott, who will chair the next ASASS meeting (ASASS
3), which will be held in Melbourne in 2018. Given the great success of ASASS 2, I have no doubt we are seeing the establishment of what will be a long lasting and successful Australian based symposium series.

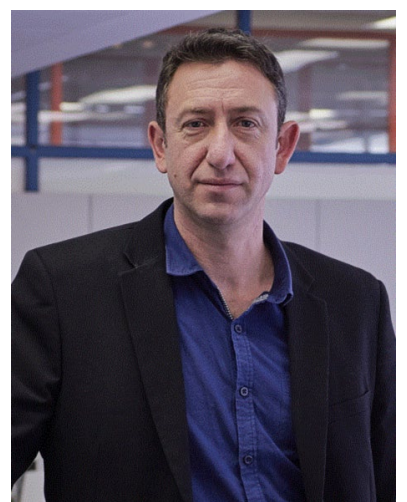

Professor Brett Paull is a University of Plymouth (UK) B.Sc. (Hons), Ph.D. and D.Sc. Graduate and a Fellow of the Royal Society of Chemistry. Brett took up his first lectureship at the University of Tasmania from 1995 to 1997 , before moving to Dublin City University (DCU), Ireland, as Lecturer (1998-2003), Senior Lecturer (2003-2006) and Associate Professor (2006-2011). In 2009, Brett was appointed Head of School of Chemical Sciences, $\mathrm{DCU}$, and the Director of the Irish Separation Science Cluster (ISSC). In 2011, Brett rejoined the University of Tasmania as a Professor of Analytical Chemistry under the University's New Stars program. Brett is currently Director of both the Australian Centre for Research on Separation Science (ACROSS), and the ARC Training Centre for Portable Analytical Separation technologies (ASTECH). Professor Paull is also the University of Tasmania Node Leader and Electrofluidics and Diagnostics Theme Leader within the ARC Centre of Excellence for Electromaterials Science. Brett has over 225 published peer reviewed papers, scholarly articles, book chapters, monographs and patents in the field of materials and analytical sciences.

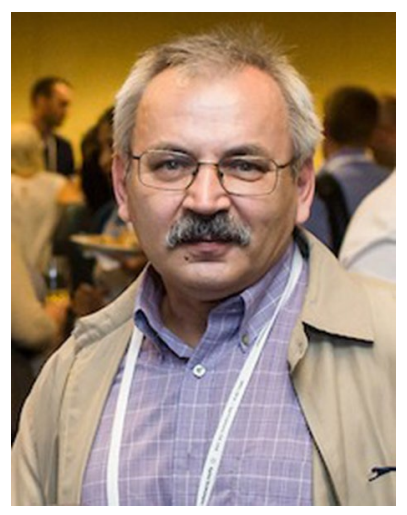

Professor Pavel N. Nesterenko received his $\mathrm{PhD}(1984)$ and DSc degrees (2000) in chemistry from Lomonosov Moscow State University (Moscow, Russia). In 2006, he moved to Australia, where he holds a position of Senior Research Fellow in School of Physical Sciences of the University of Tasmania, Hobart. He has authored more than 310 scientific publications including 3 monographs, 10 Chapters in books, 295 regular papers and holds 12 patents. His research interests are associated with development of new advanced adsorbents for various applications in separation science. He is a member of advisory and editorial boards for 7 international journals in the field of analytical chemistry and separation sciences. 